\title{
Practical behavioural solutions to COVID-19: Changing the role of behavioural science in crises
}

\author{
Charlotte C Tanis ${ }^{1, *}$, Floor H Nauta ${ }^{1}$, Meier J Boersma ${ }^{2}$, Maya V Van der Steenhoven ${ }^{2}$, \\ Denny Borsboom ${ }^{1}$, and Tessa F Blanken ${ }^{1, *}$
}

\author{
${ }^{1}$ Department of Psychological Methods, University of Amsterdam, 1018 WT Amsterdam, the Netherlands \\ ${ }^{2}$ Smart Distance Lab, 2353 NM Leiderdorp, the Netherlands \\ *Correspondence should be addressed to c.c.tanis@uva.nl or t.f.blanken@uva.nl
}

\begin{abstract}
For a very long time in the COVID-19 crisis, behavioural change leading to physical distancing behaviour was the only tool at our disposal to mitigate virus spread. In this large-scale naturalistic experimental study we show how we can use behavioural science to find ways to promote the desired physical distancing behaviour. During seven days in a supermarket we implemented different behavioural interventions: (i) rewarding customers for keeping distance; (i) providing signage to guide customers; and (iii) altering shopping cart regulations. We asked customers to wear a tag that measured distances to other tags using ultra-wide band at $1 \mathrm{~Hz}$. In total $N=4,232$ customers participated in the study. We compared the number of contacts ( $<1.5$ $\mathrm{m}$, corresponding to Dutch regulations) between customers using state-of-the-art contact network analyses. We found that rewarding customers and providing signage increased physical distancing, whereas shopping cart regulations did not impact physical distancing. Rewarding customers moreover reduced the duration of remaining contacts between customers. These results demonstrate the feasibility to conduct large-scale behavioural experiments that can provide guidelines for policy. While the COVID-19 crisis unequivocally demonstrates the importance of behaviour and behavioural change, behaviour is integral to many crises, like the trading of mortgages in the financial crisis or the consuming of goods in the climate crisis. We argue that by acknowledging the role of behaviour in crises, and redefining this role in terms of the desired behaviour and necessary behavioural change, behavioural science can open up new solutions to crises and inform policy. We believe that we should start taking advantage of these opportunities.
\end{abstract}

\section{Introduction}

Behaviour is often mentioned in relation to crises: the trading of mortgages that resulted in the financial crisis in 2008, the shaking of hands in the latest COVID-19 crisis, or the consuming of goods in the climate crisis. In most of these cases, behaviour is primarily considered as a factor that causes or sustains a crisis, but when it comes to solving a crisis, behaviour is less likely to be considered. For solutions to a crisis, we often turn to experts from the respective discipline - in the financial crisis we turn to economists ${ }^{1}$, in the COVID-19 crisis we turn to epidemiologists ${ }^{2}$, and in the climate crisis we turn to climatologists ${ }^{3}$. We seem to overlook the power of behavioural change, and the field of behavioural science, in our battle against these crises ${ }^{4}$. We should consider people's behaviour not only as causes and sustaining factors, but also turn to the solutions that behavioural change can provide.

The most recent COVID-19 crisis clearly demonstrates the role of behaviour and behavioural change ${ }^{5,6}$. The virus transmitted through behavioural contacts, and in absence of a vaccine, it was pivotal that we found ways to alter people's behaviour and promote physical distancing and hygiene to mitigate virus spread ${ }^{7}$. This need for behavioural change resulted in worldwide regulations, such as lockdowns, school closures, and travel restrictions, all directed to reduce the number of behavioural contacts. Interestingly, while the regulations focused on behavioural change, their effectiveness was assessed in terms of epidemiological parameters (e.g., the reproduction number, number of cases and deaths) ${ }^{8}$. Behavioural criteria to express the effectiveness of these regulations were largely unavailable ${ }^{9,10}$, and there was little information on how to successfully accomplish these behavioural changes.

We have seen similar patterns in other crises. Take for example the global financial crisis of 2008, where behaviour clearly played a role, e.g., through the creation of hedge funds and taking excessive risks ${ }^{11}$. In finding a solution, however, governments were inclined to turn to economical solutions and e.g., lowered the interest rates ${ }^{12}$. At the same time, there are important questions that need to be asked, such as why did people engage in this excessive risk taking behaviour, and how could other behaviour be stimulated ${ }^{13}$ Such questions are crucial to understand and prevent other financial crises, and are intrinsically of behavioural nature. In the climate crisis too, behaviour is considered as cause while predominantly technological solutions are being proposed. However, it has been increasingly vocalized that the only way to combat climate change is through 
behavioural change ${ }^{14,15}$. These examples underscore the importance of behaviour and behavioural change, not only as causing and sustaining factors of crises, but precisely also as solutions to crises.

We advocate that behavioural science plays a prominent role in finding solutions to crises, together with scientists from other fields ${ }^{16}$. In the context of the COVID-19 crisis, we need scientists from many different disciplines ${ }^{17}$ : virologists and micro-biologists to understand how the virus works ${ }^{18}$, epidemiologists on how the virus spreads ${ }^{19}$, and medical scientists on how to treat the virus ${ }^{20}$. But we also need behavioural scientists to understand how we can successfully change our behaviour and combat the virus spread. Behavioural science provides a way to link science and society, with behavioural change running like a thread out of crises.

In the current paper we demonstrate how we can put this idea into practice, and use behavioural science to provide concrete answers on how to promote the desired behaviour of physical distancing during the COVID-19 crisis, similar to our previous work in an art fair ${ }^{21}$. In this research we focused on physical distancing behaviour in public spaces, specifically in a supermarket. We identified different ways to stimulate physical distancing by considering psychological processes, crowd management, and practical solutions. Based on these, we developed different interventions: (i) rewarding customers ${ }^{22}$; (ii) providing signage to guide customers ${ }^{23}$; and (iii) altering shopping cart regulations. We directly measured the desired behaviour using wearable sensors that recorded the distance between customers. We subsequently systematically evaluated the effectiveness of these interventions in an experimental design where we varied the proposed interventions across seven days.

\section{Methods}

\section{Participants and design}

Participants in our naturalistic study were customers of the supermarket PLUS André and Joyce van Reijen in Veldhoven, the Netherlands. Veldhoven is a town of approximately 45,000 inhabitants in the southern Netherlands, located in the Metropoolregio Eindhoven. All customers older than 16 years could participate in the study, and there were no other in- or exclusion criteria.

The experiment took place during seven days in a supermarket. We varied three interventions: reward, signage, and adjusting the shopping cart regulations. Participants received the reward upon handing in their tag (see Procedure) and consisted of cookies on Saturday March $24^{\text {th }}$ and chocolate on Friday March $26^{\text {th }}$. The signage consisted of footprints in the queue for the register to indicate appropriate distance, and arrows in part of the supermarket signaling unidirectional walking directions (see Materials). Finally, we changed the shopping cart regulations from mandatory (which was standard in the Netherlands at that time) to optional. The mandatory shopping carts were implemented in the Netherlands in March $2020^{24}$ to (1) keep track of the number of participants in the supermarket as national regulations allowed a maximum of 1 customer per $10 \mathrm{~m}^{2}$, and (2) as the shopping carts were thought to facilitate physical distancing. We varied the interventions across days, resulting in a unique set of interventions for each day, see Table 1. Each day we handed out sensors between 12:00 and 17:00. The supermarket communicated via posters that every day between 14:00 and 15:00 was intended for older and vulnerable people to do their groceries, but this was not actively enforced.

\begin{tabular}{|c|c|c|c|c|c|c|}
\hline & \multirow[t]{3}{*}{ day } & \multicolumn{4}{|c|}{ intervention } & \multirow[t]{3}{*}{ comparison } \\
\hline & & \multirow[t]{2}{*}{ reward } & \multicolumn{2}{|c|}{ signage } & \multirow[t]{2}{*}{ space } & \\
\hline & & & arrows & footprints & & \\
\hline 1 & 17 March 2021 & & & & & space \\
\hline 2 & 18 March 2021 & & & & $\checkmark$ & \\
\hline 3 & 19 March 2021 & & & & $\checkmark$ & space, signage \\
\hline 4 & 20 March 2021 & $\checkmark$ & & & $\checkmark$ & \\
\hline 5 & 24 March 2021 & & & $\checkmark$ & & \\
\hline 6 & 25 March 2021 & & $\checkmark$ & $\checkmark$ & $\checkmark$ & signage, reward \\
\hline 7 & 26 March 2021 & $\checkmark$ & $\checkmark$ & $\checkmark$ & $\checkmark$ & reward \\
\hline
\end{tabular}

Table 1. Experimental design.

\section{Materials \\ Physical distance}

Participants wore a SafeTag developed by KINEXON (https://kinexon.com/technology/safetag/). SafeTags are wearable tags that measure the distance to other SafeTags at a frequency of one Hz using ultra-wideband (UWB) technology with an accuracy 
up to $10 \mathrm{~cm}$. A tag automatically turns on and starts measuring when taken out of its charging unit, and turns back off when placed back into the unit. Each tag has a unique tag id and locally stores measured distances until the data is read out on a laptop running the management software. The tags were solely used to measure physical distance, and did not provide any form of feedback.

\section{Shopping experience}

We asked participants to rate their shopping experience on an iPad. Participants were asked to rate three questions on a five-point scale from satisfied to dissatisfied (indicated by five emoticons): (1) How did you experience the corona regulations in the supermarket? ('regulations'); (2) How pleasant was it to do groceries like this? ('pleasantness'); (3) Did you feel you were helped to keep a distance? ('help').

\section{Camera and traffic light}

National regulations specified a maximum number of customers inside the supermarket (i.e., one customer per $10 \mathrm{~m}^{2}$ ). The mandatory shopping cart allowed to keep track of the number of participants inside. In order to be able to relax the mandatory shopping cart but still adhere to national regulations, we installed a camera at the entrance of the supermarket that counted all incoming customers. The camera was linked to a traffic light that indicated to incoming customers how crowded the supermarket was (green: few people inside; orange: quite busy, be aware of your distance; red: full capacity reached, wait until someone exits). The camera registered all incoming and outgoing customers which was saved to a database and could be retrieved per hour.

\section{Signage}

We had two types of signage in the supermarket: waiting signage in the queue for the register and arrows depicting unidirectional walking directions in part of the supermarket where the aisles were too narrow to keep $1.5 \mathrm{~m}$ distance. The waiting signage consisted of round stickers with footprints on them and were placed $1.5 \mathrm{~m}$ from one another. The arrows were also placed 1.5 $\mathrm{m}$ from one another, to both signal the unidirectional walking directions as well as the appropriate physical distance.

\section{Procedure}

In the week prior to our experiment (week 10, 2021), flyers were passively distributed alongside the ad brochure in the supermarket, to inform customers of the upcoming experiment on the effectiveness of physical distancing regulations. The flyer informed participants when the study would take place, and stressed the voluntary character of the experiment.

The experiment itself took place in week 11 from Wednesday March $17^{\text {th }}$ until Saturday March $20^{\text {th }}$ and week 12 from Wednesday March $24^{\text {th }}$ until Friday March 26 $6^{\text {th }} 2021$. Outside of the supermarket, a team member informed customers that a study would take place inside the supermarket, for which they could participate on voluntary basis. On days that shopping carts were not mandatory, customers were additionally informed that they could enter without taking one. Inside, customers were asked to participate in the experiment. In case customers had additional questions about the study, a team member explained the study in more detail and provided the original information flyer. If customers agreed to participate, we handed them a SafeTag to wear on a lanyard around their neck, and registered their implicit informed consent. In conditions in which a reward was handed out, we also informed participants that they would receive a reward for their effort to keep their distance upon handing in their SafeTag. Participants could then proceed to do their groceries like they would otherwise do. After paying at the register, participants could rate their satisfaction with the supermarket visit. A desk to hand back the tags was located at the exit of the supermarket. Both the tags and lanyards were thoroughly cleaned before they were handed out again to other customers.

The ethics review board of the University of Amsterdam approved the study and implicit informed consent because of the voluntary and anonymous nature of the study (2021-PML-13247).

\section{Analysis \\ Pre-processing}

The raw data from the SafeTags contains for each assessment (frequency of $1 \mathrm{~Hz}$ ) a time stamp, the tag id of the reporting and opposing tag, and the distance between them in centimetres. Since tags were handed out multiple times during one day, we first determined the start and end time of each participant wearing the tag to construct unique participant id's. We then checked if participants entered the supermarket as a group, e.g., two people doing groceries together. We assigned participants as belonging to the same group if they met at least two of the following criteria: at least 10 contacts within $80 \mathrm{~cm}$, being within $1.5 \mathrm{~m}$ of each other for at least $25 \%$ of their visit duration, and exiting the supermarket at most 60 seconds after each other. If at least two of these criteria were met, we removed all contacts between the respective group members. We considered two participants to be in contact with one another if (a) they did not belong to the same group and (b) were within $1.5 \mathrm{~m}$ from one another, in accordance with the physical distance regulations at the time in the Netherlands. To compute the contact duration between two customers, we summed the duration of all registered contacts between two participants. 


\section{Descriptive analyses}

We first performed a simple linear regression to assess the effect of crowdedness on the median number of unique contacts per hour. As was found in other studies ${ }^{25}$ it is conceivable that the busier it is, the more difficult it becomes to keep a physical distance. If this is the case, then we should control for this effect by comparing conditions at times that were similar in crowdedness.

To evaluate the effectiveness of each intervention in isolation, we select two conditions that differ only in regard to whether the behavioural intervention of interest is implemented. For each intervention, we tested the difference in the number of unique contacts between participants with a Bayesian logistic regression model (see Contact networks), and in contact duration with a Mann-Whitney U test. In addition, we tested differences in ratings of shopping experience (i.e., regulations, pleasantness, and help) with two sample t-tests using all available data from that day.

\section{Contact networks}

To compute differences in number of contacts between participants, we analyzed the contact networks with a Bayesian logistic regression model, developed for our previous study, called the $\mathrm{b} 2$ model $^{21}$. The b2 model is a reduced version of the multilevel p2 model $^{26}$, for undirected (i.e., a contact is always shared between two people) and unweighted (i.e., a contact is binary and duration is not taken into account) networks. The model omits reciprocity parameters, dyadic predictors, and random effects at the network level, and contains identical random sender and receiver effects. We modeled differences in the number of unique contacts between two contact networks with actor-level dummy variables. Estimating the b2 model was done in a similar manner as the $\mathrm{j} 2$ model $^{27,28}$, using Markov Chain Monte Carlo simulation and similar prior distributions. For all comparisons, we report the posterior means as point estimates for the odds ratios accompanied by the corresponding $95 \%$ credible interval. The credible interval describes the range where the true odds ratio lies with $95 \%$ certainty.

All analyses were performed in R (version: 4.1.1) and the dyads (1.1.4) package ${ }^{29}$ was used to compare the contact networks.

\section{Results}

\section{Visitors}

A total of $N=4,232$ customers participated in our study. The number of customers inside the supermarket varied over time, and we first investigated whether there was an effect between crowdedness and the number of contacts per hour. Figure 1 shows that there exists a relation between the number of customers inside as registered by the camera at the entrance, and the median number of contacts per hour $\left(F(1,28)=10.89, p=.003, R^{2}=.28\right)$. To minimize the influence of sample size on the effects of interventions, we selected comparable hours in terms of the time of day, number of customers inside the supermarket, and number of customers participating in our study (compliance), see Table 2.

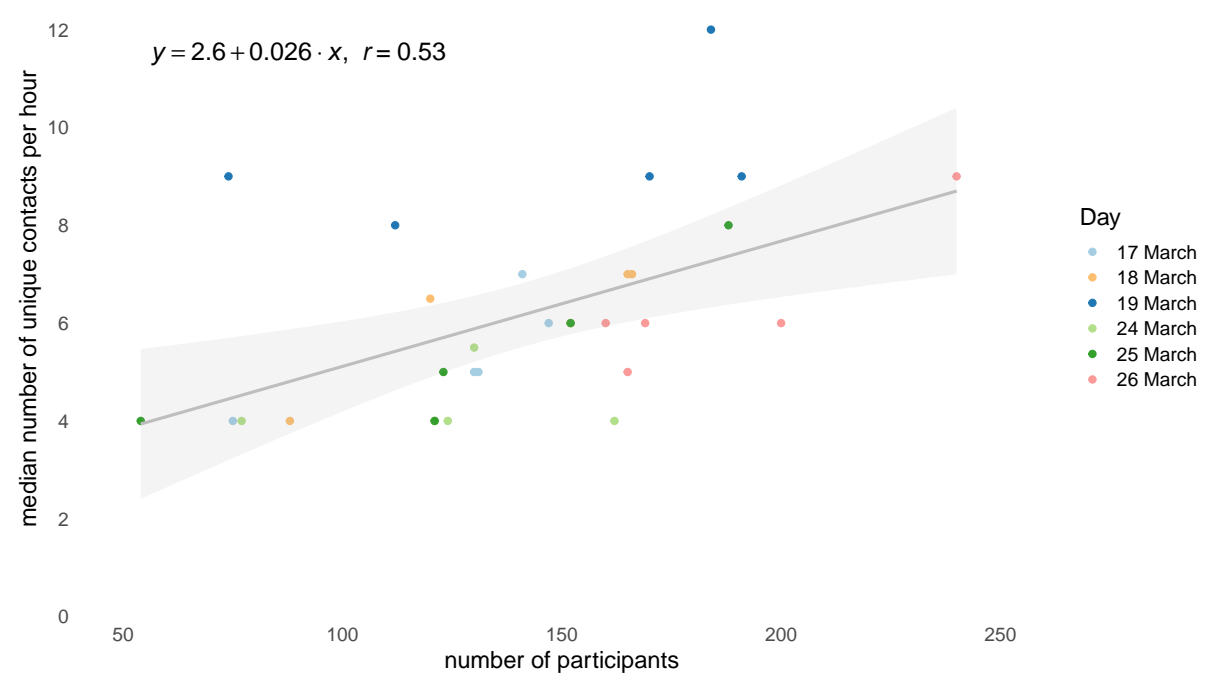

Figure 1. Relationship between the number of participants and the median number of unique contacts in one-hour time windows across six days. 


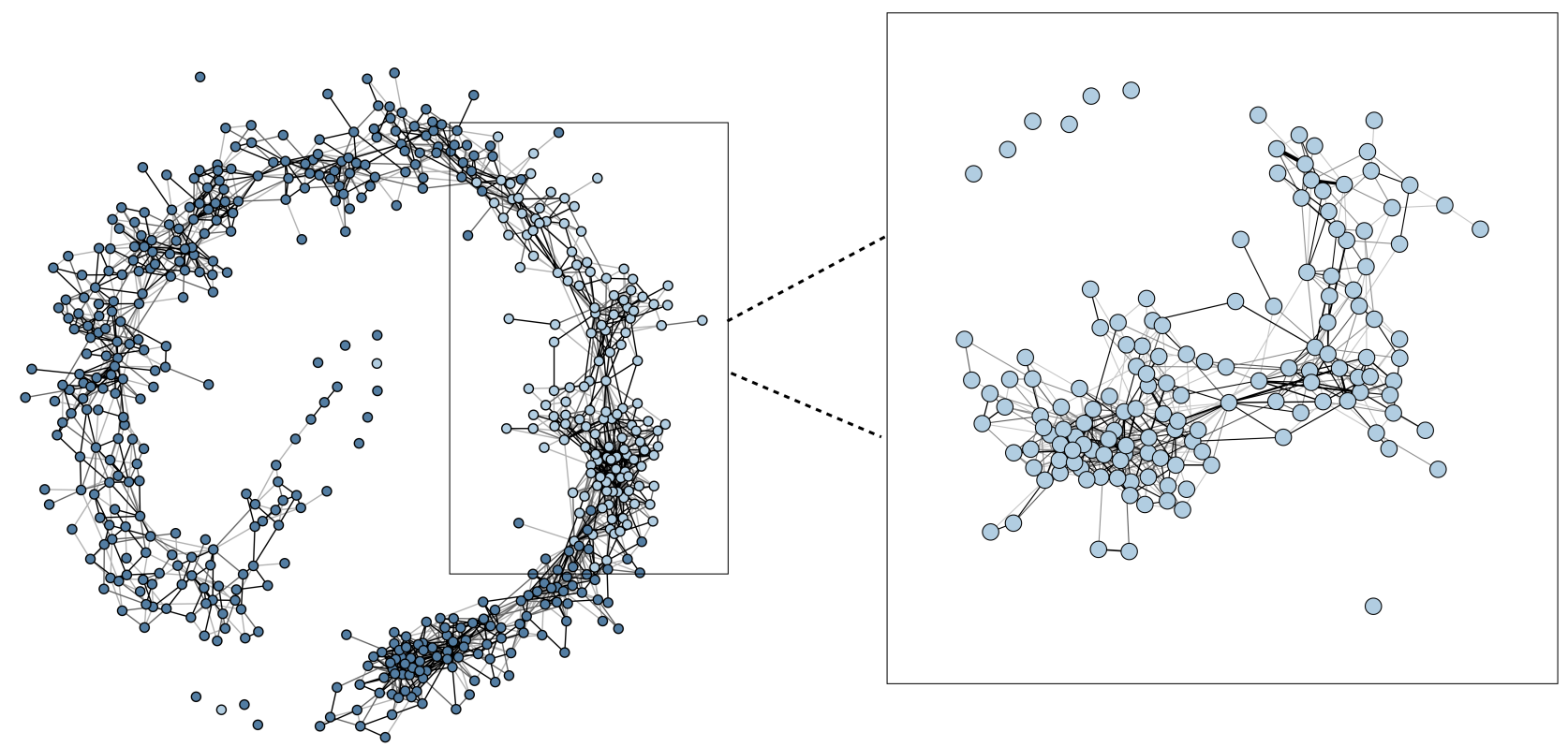

Figure 2. The contact network of $n=624$ participants on March $17^{\text {th }}$ is shown on the left. All participants are represented as nodes, and two participants are linked when they came within $1.5 \mathrm{~m}$. The links are weighted by their contact duration. The highlighted nodes indicate the participants present between 15:00 and 16:00, the time slot we selected for the comparison. A detailed view of the contact network of these included participants is shown on the right.

\section{Contact network}

To evaluate the effectiveness of behavioural interventions on physical distancing we followed the experimental framework proposed by Blanken et al. (2021) $)^{21}$ in which participants and their contacts are represented in a contact network. This representation allows to take the network structure into account when comparing two conditions 9 .

Figure 2 shows the contact network of the $n=624$ participants included on the first day of our study. Each participant is represented as a node, and whenever two participants came within $1.5 \mathrm{~m}$ of each other, they are connected by a link. The highlighted nodes indicate $n=147$ participants present between 15:00 and 16:00 that were included in the analysis.

\section{Interventions}

\section{Reward}

To examine the psychological effect of rewarding participants on their physical distancing behaviour, we compared the contact network on day 6 (no reward) with the contact network of day 7 (reward). As can be seen in Table 2, participants who received a reward had a median of 6 unique contacts, whereas without a reward participants had a median of 8 unique contacts. Detailed analysis taking the network structure of the data into account showed that the probability of forming contacts was lower when participants received a reward $(\mathrm{OR}=0.83,95 \%$ Credible Interval $(\mathrm{CI})[0.71,0.97])$. The $\mathrm{CI}$ indicates some uncertainty about the size of the effect, but rewarding participants for their effort to keep a distance improves physical distancing. In addition, participants who received a reward had slightly shorter contacts (median of 4.2 seconds) than participants who did not receive a reward (median of 5.9 seconds; $U=21606, p<0.001$ ). Finally, participants' ratings of the regulations, pleasantness, and help did not differ between the two conditions (all $p>0.2$ ).

\section{Signage}

To examine the effect of signage on physical distancing, we compared the contact network on day 3 without signage, to the contact network on day 6 , when footprints and arrows were provided. The median number of unique contacts of participants was 9 without signage, and 6 when signage was provided. The probability of participants forming contacts was lower when providing signage compared to the situation where no signage was provided $(\mathrm{OR}=0.85,95 \% \mathrm{CI}[0.71,1.00])$. The $\mathrm{CI}$ around this estimate shows that there is some uncertainty about the size of the effect and the upper limit is equal to 1 , but indicates 


\begin{tabular}{|c|c|c|c|c|c|c|c|c|c|c|c|c|c|c|c|c|}
\hline \multirow[t]{2}{*}{ condition } & & \multirow[t]{2}{*}{ day } & \multirow[t]{2}{*}{$n_{\text {reg }}$} & \multirow[t]{2}{*}{$n_{\text {part }}(\%)$} & \multicolumn{4}{|c|}{ number of contacts } & \multicolumn{4}{|c|}{ contact duration } & \multicolumn{4}{|c|}{ experience } \\
\hline & & & & & range & $M \pm S D$ & median & IQR & range & $M \pm S D$ & median & IQR & $n$ & regulation & pleasantness & help \\
\hline \multicolumn{17}{|l|}{ reward: } \\
\hline no & 6 & $16-17 \mathrm{~h}$ & 275 & $188(68 \%)$ & $0-24$ & $8.4 \pm 5.3$ & 8 & $4-12$ & $2-22$ & $7.0 \pm 4.0$ & 5.9 & $4.0-8.5$ & 240 & $4.3 \pm 0.8$ & $4.0 \pm 0.9$ & $4.1 \pm 0.9$ \\
\hline yes & 7 & $15-16 \mathrm{~h}$ & 316 & $200(63 \%)$ & $0-26$ & $6.7 \pm 5.1$ & 6 & $3-9$ & $2-28$ & $5.6 \pm 4.1$ & 4.2 & $3.2-6.6$ & 238 & $4.2 \pm 0.8$ & $4.0 \pm 0.9$ & $4.1 \pm 0.8$ \\
\hline \multicolumn{17}{|l|}{ signage: } \\
\hline no & 3 & $15-16 \mathrm{~h}$ & 237 & $170(72 \%)$ & $0-33$ & $9.5 \pm 6.3$ & 9 & 4-13 & $2-44$ & $6.8 \pm 4.7$ & 5.6 & $4.3-8.0$ & 194 & $4.1 \pm 0.9$ & $3.7 \pm 1.0$ & $3.9 \pm 0.9$ \\
\hline yes & 6 & $15-16 \mathrm{~h}$ & 222 & $152(68 \%)$ & $0-27$ & $6.1 \pm 4.5$ & 6 & $3-8$ & $2-36$ & $7.0 \pm 5.9$ & 4.8 & $3.6-8.0$ & 240 & $4.3 \pm 0.8$ & $4.0 \pm 0.9$ & $4.1 \pm 0.9$ \\
\hline \multicolumn{17}{|l|}{ shopping carts: } \\
\hline mandatory & 1 & $15-16 \mathrm{~h}$ & 204 & $147(72 \%)$ & $0-27$ & $7.7 \pm 5.7$ & 6 & $4-10$ & $2-48$ & $7.4 \pm 5.9$ & 6.0 & $4.0-8.7$ & 324 & $4.2 \pm 0.8$ & $3.8 \pm 1.0$ & $3.9 \pm 1.0$ \\
\hline optional & 3 & $15-16 \mathrm{~h}$ & 237 & $170(72 \%)$ & $0-33$ & $9.5 \pm 6.3$ & 9 & $4-13$ & $2-44$ & $6.8 \pm 4.7$ & 5.6 & $4.3-8.0$ & 194 & $4.1 \pm 0.9$ & $3.7 \pm 1.0$ & $3.9 \pm 0.9$ \\
\hline
\end{tabular}

Table 2. Descriptives. Note: $n_{\text {reg }}$ indicates the number of incoming customers, as registered by the camera at the entrance, and $n_{\text {part }}$ indicates the number of customers who agreed to wear a tag and participate in the study.

that signage is likely to have a positive effect on physical distancing. Finally, contact duration did not differ significantly between conditions $(U=13038, p=0.07)$, but participants in the signage condition rated their experience regarding regulations $(t(383.24)=2.18, p=.03)$, pleasantness $(t(375.51)=3.41, p<.001)$ and help $(t(373.54)=2.54, p=.01)$ more satisfactory than participants in the no signage condition.

\section{Shopping cart}

To examine the effect of altering shopping cart regulations, we compared the contact network on day 1, when a shopping cart was mandatory, with the contact networks on day 3 , when the shopping cart was optional. On day 1 with mandatory shopping carts, participants had a median of 6 unique contacts, compared with a median of 9 unique contacts on day 3 , when the shopping carts were optional. Despite these numerical differences, detailed analyses taking the network structure into account indicate that the probability of participants forming contacts was about the same in these two conditions (OR $=1.07,95 \%$ CI $[0.90,1.26]$ ), indicating that if the number of contacts are different between mandatory and optional shopping carts, these differences are likely to be small. Thus, mandatory shopping carts do not appear to facilitate nor inhibit physical distancing. In addition, the contact duration did not differ significantly between conditions $(U=11724, p=0.68)$, and mandatory or optional shopping carts did not change participants' ratings (all $p>0.1$ ).

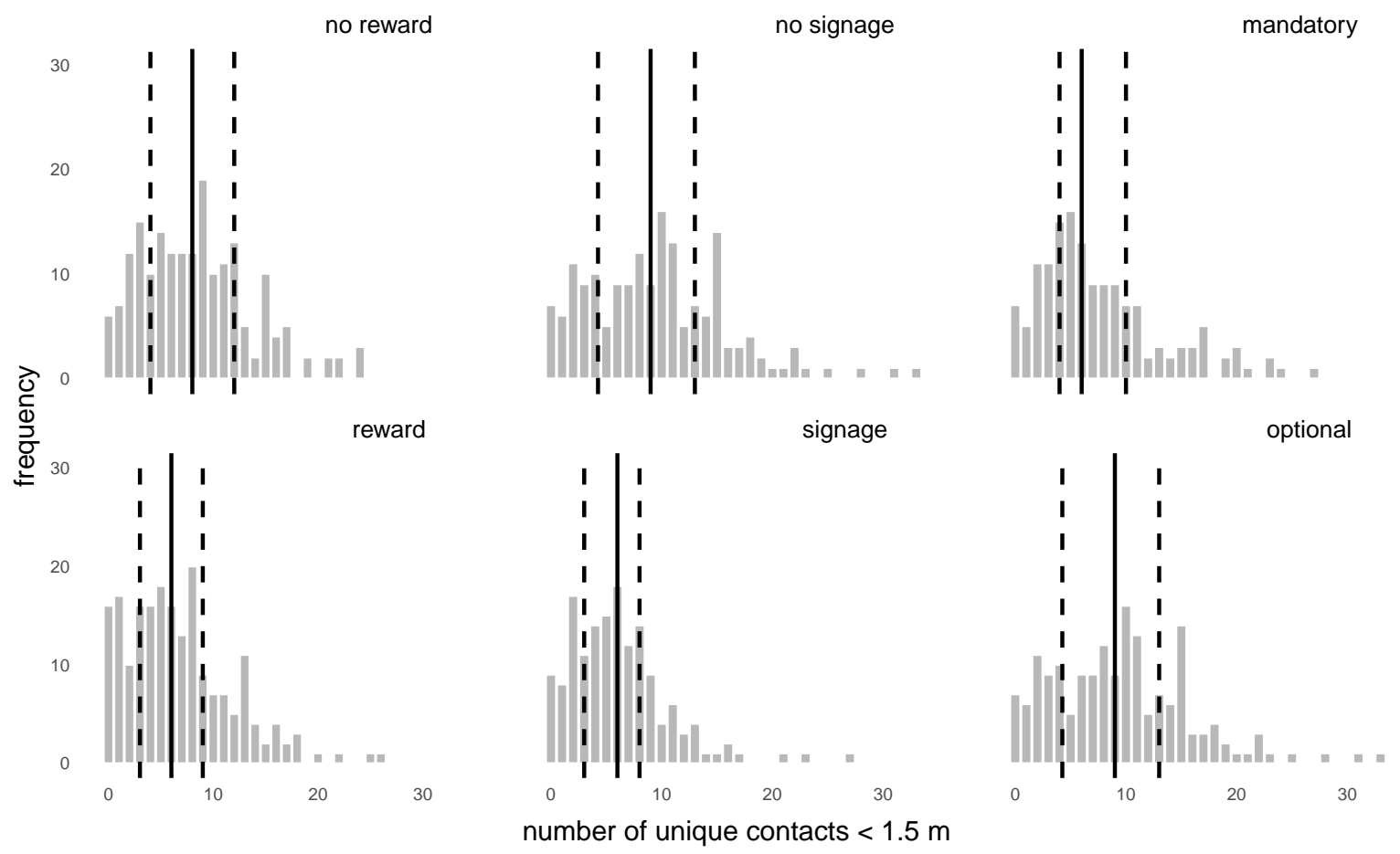

Figure 3. The number of unique contacts $(<1.5 \mathrm{~m})$ in each of the six conditions. The solid line represents the median, and the two dashed lines the $25^{\text {th }}$ and $75^{\text {th }}$ percentiles, such that $50 \%$ of the observations fall within the two dashed lines. 


\section{Discussion}

In this paper we demonstrated how behavioural science can be used in response to crises by evaluating the effectiveness of interventions targeted to achieve the desired behavioural change. We applied this idea to the COVID-19 crisis and performed a behavioural experiment to investigate the effectiveness of behavioural interventions to promote physical distancing. We did so by implementing three interventions (i.e., reward, signage, shopping cart regulations) and evaluated their effect on the contacts between customers (i.e., a distance within $1.5 \mathrm{~m}$ ). Our results demonstrate that rewarding customers for keeping their distance and providing signage both improved physical distancing and reduced the number of contacts. Interestingly, rewarding customers not only reduced the number of contacts, but also shortened the duration of the remaining contacts. In contrast, mandatory or optional shopping cards did not appear to improve or worsen physical distance behaviour. Overall, participants rated their shopping experience as satisfactory, and most of the regulations did not impact these ratings. In fact, signage was rated more positively on all accounts (regulations, pleasantness, perceived help) than no signage.

The current study showed how we can use behavioural science to find practical behavioural solutions to crises. Starting out with an existing problem, we defined a desired behaviour to combat this problem, and found a way to directly measure this behaviour. Subsequently, based on the desired behaviour, we identified different interventions designed to stimulate this behaviour. These interventions can be based on psychological mechanisms (e.g., rewarding participants), but can also be informed by other fields, like in our case crowd management. Ultimately, the aim is to promote the desired behaviour, and any intervention targeted at this can be tested within the experimental design. In an experimental design we systematically varied the interventions, such that we could analyse the effect of each of the interventions on the desired behaviour. Investigating the identified interventions in an experimental design is a crucial step, as behavioural solutions have to be tested (in the crisis situation) before they can be translated into policy ${ }^{30}$. Finally, the insights derived from the experiment can directly inform policy recommendations, making behavioural science a central link connecting science with society.

In Table 3 we outline the steps described above with concrete examples that we took in identifying behavioural solutions to COVID-19. Crucially, these steps transcend the COVID-19 crisis and can be applied much broader to other crises as well. For the financial crisis as well as the climate crisis these steps can similarly shed light on possible practical behavioural solutions for which we give an illustrative example and accompanying reference in Table 3. These are just a few examples, and the (behavioural) factors involved in these crises are much more complicated than can be captured in a simple Table. Nonetheless, in each of these crises, behavioural factors played an important role. Rather than viewing these factors just as causing or sustaining a crises, they can also provide an avenue towards solution out of that crisis.

\begin{tabular}{|c|c|c|c|}
\hline & COVID-19 crisis & Global Financial Crisis & climate crisis \\
\hline problem & virus transmission & housing bubble & greenhouse gas emission \\
\hline desired behaviour & physical distancing & reduce risk taking & increase vegetarian diets \\
\hline direct measurement & $\begin{array}{l}\text { physical distances between people } \\
\text { measured using UWB }\end{array}$ & propensity to sell assets & number of vegetarian dishes sold \\
\hline intervention & $\begin{array}{l}\text { psychological mechanism: reward }{ }^{22} \\
\text { pedestrian behaviour: follow signage } \\
\text { practical: adjust shopping cart regulations }\end{array}$ & $\begin{array}{l}\text { psychological mechanism: salience }{ }^{31} \\
\text { disposition effect }^{11}\end{array}$ & $\begin{array}{l}\text { psychological mechanism: } \text { salience }^{31} \\
\text { practical: visibility }\end{array}$ \\
\hline $\begin{array}{l}\text { experimental design } \\
\text { and analysis }\end{array}$ & see current paper & see Frydman \& Rangel $(2014)^{32}$ & see Kurz $(2018)^{33}$ \\
\hline policy recommendation & reward people for keeping their distance & $\begin{array}{l}\text { decrease salience of information } \\
\text { related to capital gains }\end{array}$ & increase salience of vegetarian dishes \\
\hline
\end{tabular}

Table 3. Examples on how behavioural science can be used to develop effective interventions to stimulate desired behaviour.

While our experimental study provides indications for practical behavioural solutions, there are some limitations that warrant attention. First, because of the naturalistic nature of the study it was not possible to randomize the participants over experimental conditions. As a result, there are several factors that we could not control, like the type of customers or the number of customers in each experimental condition. To limit this variation, we measured during the same days over a two-week time period. In addition, to compare the effectiveness of interventions we selected times during the day that were similar in crowdedness and time of day. Still, it could be possible that some interventions work differently depending on the crowdedness. For example, mandatory shopping carts could potentially facilitate physical distancing in quiet times, but actually crowd the supermarket even more during rush-hours. In the current naturalistic experiment, these factors are hard to disentangle.

Second, it might be challenging to implement some of our findings into practice. For example, we showed that rewarding participants improved physical distancing, but it might be challenging to implement these rewards structurally as supermarkets are frequently visited places. The one-off rewards could be promising for locations that people visit less often (e.g., a cinema or festival), but a different reward scheme might be necessary to achieve long term effects in a supermarket. Third, the experience assessments were only filled out by some of the participants (between 25-51\%), possibly introducing some selection bias. 
Last, all behavioural interventions we investigated were implemented in the context of a supermarket. To translate these findings to other situations it is important to consider relevant characteristics of different contexts. For example, in supermarkets people are likely to move constantly, and often visit a fixed set of locations corresponding to one's shopping list. These characteristics may be substantially different from other situations, such as using public transport (where people may have to wait for their train to arrive), or visiting a museum (where people often visit an entire exhibition). In a previous study we showed that walking directions also facilitated physical distancing at an art fair ${ }^{21}$, indicating that walking directions may be applicable both in situations where people plan their own stops (as in the supermarket) and in situations where people follow pre-specified routes and stops (as in the art fair).

To conclude, in this paper we have shown how we can find practical behavioural solutions to a crisis by defining and evaluating the desired behaviour in an experimental design. Of course, behavioural science alone will not offer the complete package to combat an entire crisis by itself. We need multidisciplinary collaborations to battle the multifaceted and complex problems of our time ${ }^{16}$. In these collaborations, behavioural science and behavioural change can provide new ways to look at existing (and new) challenges. We should start to take advantage of the opportunities offered by behavioural science.

\section{References}

1. Crotty, J. Structural causes of the global financial crisis: a critical assessment of the 'new financial architecture'. Camb. J. Econ. 33, 563-580, DOI: 10.1093/cje/bep023 (2009).

2. Lipsitch, M., Swerdlow, D. L. \& Finelli, L. Defining the Epidemiology of Covid-19 - Studies Needed. New Engl. J. Medicine 382, 1194-1196, DOI: 10.1056/NEJMp2002125 (2020).

3. Masson-Delmotte, V. et al. IPCC: Climate Change 2021: The Physical Science Basis. Tech. Rep. (2021).

4. Creutzig, F. et al. Towards demand-side solutions for mitigating climate change. Nat. Clim. Chang. 8, 268-271, DOI: 10.1038/s41558-018-0121-1 (2018).

5. Behaviour fuels, and fights, pandemics. Nat. Hum. Behav. 4, 435, DOI: 10.1038/s41562-020-0892-z (2020).

6. Bavel, J. J. V. et al. Using social and behavioural science to support COVID-19 pandemic response. Nat. Hum. Behav. 4, 460-471, DOI: 10.1038/s41562-020-0884-z (2020).

7. Betsch, C. How behavioural science data helps mitigate the COVID-19 crisis. Nat. Hum. Behav. 4, 438, DOI: 10.1038/ s41562-020-0866-1 (2020).

8. Flaxman, S. et al. Estimating the effects of non-pharmaceutical interventions on COVID-19 in Europe. Nature 584, 257-261, DOI: 10.1038/s41586-020-2405-7 (2020).

9. Borsboom, D. et al. The lighting of the BECONs: A behavioral data science approach to tracking interventions in COVID-19 research. Preprint at https://psyarxiv.com/53ey9 (2020).

10. Hoeben, E. M., Bernasco, W., Suonperä Liebst, L., van Baak, C. \& Rosenkrantz Lindegaard, M. Social distancing compliance: A video observational analysis. PLOS ONE 16, e0248221 (2021).

11. Szyszka, A. Behavioral Anatomy of the Financial Crisis. J. CENTRUM Cathedra (2010).

12. Claessens, S., Dell'Ariccia, G., Igan, D. O. \& Laeven, L. Lessons and Policy Implications from the Global Financial Crisis. IMF Work. Pap. 2010, A001, DOI: 10.5089/9781451963021.001.A001 (2010).

13. Dedu, V., Sebastian, T. C. \& Radu, T. A BEHAVIORAL APPROACH TO THE GLOBAL FINANCIAL CRISIS. Annals Fac. Econ. 1, 340-346 (2011).

14. Gosnell, G. K. \& Bazilian, M. D. Changing behaviour is the key to solving the climate challenge. Nat. Hum. Behav. 5, 294, DOI: 10.1038/s41562-020-01047-8 (2021).

15. van de Ven, D.-J., González-Eguino, M. \& Arto, I. The potential of behavioural change for climate change mitigation: a case study for the European Union. Mitig. Adapt. Strateg. for Glob. Chang. 23, 853-886, DOI: 10.1007/s11027-017-9763-y (2018).

16. Sturmberg, J. P. \& Martin, C. M. COVID-19 - how a pandemic reveals that everything is connected to everything else. J. Eval. Clin. Pract. 26, 1361-1367, DOI: 10.1111/jep.13419 (2020).

17. Chams, N. et al. COVID-19: A Multidisciplinary Review. Front. public health 8, 383, DOI: 10.3389/fpubh.2020.00383 (2020).

18. Jin, Y. et al. Virology, Epidemiology, Pathogenesis, and Control of COVID-19, DOI: 10.3390/v12040372 (2020). 
19. Anderson, R. M., Heesterbeek, H., Klinkenberg, D. \& Hollingsworth, T. D. How will country-based mitigation measures influence the course of the COVID-19 epidemic? The Lancet 395, 931-934, DOI: 10.1016/S0140-6736(20)30567-5 (2020).

20. Baden, L. R. \& Rubin, E. J. Covid-19 - The Search for Effective Therapy. New Engl. J. Medicine 382, 1851-1852, DOI: 10.1056/NEJMe2005477 (2020).

21. Blanken, T. F. et al. Promoting physical distancing during COVID-19: a systematic approach to compare behavioral interventions. Sci. Reports 11, 19463, DOI: 10.1038/s41598-021-98964-z (2021).

22. Richter, G., Raban, D. R. \& Rafaeli, S. Studying Gamification: The Effect of Rewards and Incentives on Motivation BT - Gamification in Education and Business. 21-46, DOI: 10.1007/978-3-319-10208-5\{_\}2 (Springer International Publishing, Cham, 2015).

23. Meis, J. \& Kashima, Y. Signage as a tool for behavioral change: Direct and indirect routes to understanding the meaning of a sign. PLOS ONE 12, e0182975-e0182975, DOI: 10.1371/journal.pone.0182975 (2017).

24. CBL. Winkelwagen verplicht, maximaal aantal klanten tegelijk in supermarkt. https://www.cbl.nl/winkelwagen-verplichtmaximaal-aantal-klanten-tegelijk-in-supermarkt/ (2020).

25. Pouw, C. A. S., Toschi, F., van Schadewijk, F. \& Corbetta, A. Monitoring physical distancing for crowd management: Real-time trajectory and group analysis. PLOS ONE 15, e0240963 (2020).

26. Zijlstra, B. J. H., van Duijn, M. A. J. \& Snijders, T. A. B. The Multilevel p2 Model A random effects model for the analysis of multiple social networks., DOI: 10.1027/1614-2241.2.1.42 (2006).

27. Zijlstra, B. J. H. Regression of directed graphs on independent effects for density and reciprocity. The J. Math. Sociol. 41, 185-192, DOI: 10.1080/0022250X.2017.1387858 (2017).

28. Van Duijn, M. A., Snijders, T. A. \& Zijlstra, B. J. p2: A random effects model with covariates for directed graphs. Stat. Neerlandica 58, 234-254, DOI: 10.1046/j.0039-0402.2003.00258.x (2004).

29. Zijlstra, B. J. dyads: Dyadic Network Analysis (2021).

30. IJzerman, H. et al. Use caution when applying behavioural science to policy. Nat. Hum. Behav. 4, 1092-1094, DOI: 10.1038/s41562-020-00990-w (2020).

31. Taylor, S. E. \& Fiske, S. T. Salience, Attention, and Attribution: Top of the Head Phenomena11Research described in this chapter and preparation of the chapter itself were supported by research grants from NIMH $(25827,26460$, and 26919) and from NSF (BNS77-009922) to the senior autho. vol. 11, 249-288, DOI: https://doi.org/10.1016/S0065-2601(08)60009-X (Academic Press, 1978).

32. Frydman, C. \& Rangel, A. Debiasing the disposition effect by reducing the saliency of information about a stock's purchase price. J. Econ. Behav. \& Organ. 107, 541-552, DOI: https://doi.org/10.1016/j.jebo.2014.01.017 (2014).

33. Kurz, V. Nudging to reduce meat consumption: Immediate and persistent effects of an intervention at a university restaurant. J. Environ. Econ. Manag. 90, 317-341, DOI: https://doi.org/10.1016/j.jeem.2018.06.005 (2018).

\section{Acknowledgements}

We would like to thank André and Joyce van Reijen for opening up their supermarket to run this experiment, and PLUS for printing all signage. We thank our team that helped collecting the data: Frederike Meijer, Sonja van Meerbeek, Zuzana Wilms, Henk Nieweg, Nina Leach, and Lander Arteaga. The research project was supported by the Ministry of Economic Affairs and Climate Policy. CT and TB were supported by an Innovation Exchange Amsterdam UvA Proof of Concept Fund.

\section{Author contributions statement}

CT, MB, and TB developed the study design. MB, MvdS, and TB organised the production around data collection. All authors collected the data. FN processed the data and ran the statistical analyses under supervision of CT and TB. CT and TB drafted the manuscript. All authors commented on the manuscript, and reviewed and approved the final manuscript.

\section{Additional information}

The authors declare no competing interests. 